

\title{
Thermo-Hygral Case-Study on Full Scale RC Building under Corrosive Environment and Seismic Actions
}

\author{
Nobuhiro Chijiwa $^{1}$ and Koichi Maekawa ${ }^{2 *}$
}

\begin{abstract}
This paper is to apply the multi-scale thermo-hygro-mechanistic modeling to full-scale RC structural systems under combined long-term ambient and short seismic actions. The authors also aim to dissolve numerical difficulty for full-scale performance assessment of huge degree-of-freedom. First, the multi-scale modeling is experimentally checked by using corroded RC columns under high axial compression. Second, the steel corrosion is computationally reproduced to a multi-story RC building under long-term fictitious ambient conditions. The seismic ground motion is subsequently applied to the corrosion damaged mockup. Beforehand, the effect of drying shrinkage, which is inevitable for structural concrete in air, is discussed so as to clarify the pure corrosion impact to the whole structural system. The steel corrosion deteriorates the ductility of seismic resistant members, but as a global influence, steel corrosion is validated to reduce the base-shear input of floors owing to the decayed stiffness by corrosion. Through these case-studies, the authors raise the points of discussion to take into account the local and global effects of corrosion all at once for seismic performance assessment, and that the knowledge solely on the capacity of corroded RC members cannot lead to an engineering solution.
\end{abstract}

\section{Introduction}

Corrosion of reinforcing bars is one of the major issues on durability and damage of reinforced concrete (RC), and has received engineering attention for the past decades. These efforts have brought about two achievements; one is the knowledge base of mechanism and the technology to predict the rate of steel corrosion in concrete. The other is the study on structural capacity, ductility and safety of corroded RC members.

The former category mainly focuses on somehow micro and/or meso-scale fields around reinforcing bars in concrete specimens, which is rather smaller than the size of actual buildings and infrastructure facilities. Especially, the limit state associated with corrosive crack initiation has been targeted of interest (Cabrera et al. 1996; Wong et al. 2010; Oh et al. 2009; Ouglova et al. 2006; Andrade et al. 1993; Val et al. 2009; Michel et al. 2013), and the mechanism and the rate of corrosion after cracking of cover concrete are being investigated. As a matter of fact, the crack kinematics is also governed by structural shapes, dimensioning and boundary conditions. It implies that the mutual interaction of structural mechanics and corrosion rate has been less investigated (Toongoenthong and Maekawa 2005).

The latter category deals with macroscopic or member

\footnotetext{
${ }^{1}$ Assistant Professor, Department of Civil Engineering, Tokyo Institute of Technology, Japan.

${ }^{2}$ Distinguished Professor, Department of Civil Engineering, The University of Tokyo, Japan.

Corresponding author,

E-mail: maekawa@concrete.t.u-tokyo.ac.jp
}

scale structural concrete after corrosion cracking, and focus on member based performances (Okada et al. 1988; Lee et al. 1998; Satoh et al. 2003; Sawabe et al. 2006; Yamamoto and Miyagawa 2007; Chijiwa et al. 2010; Xue and Seki 2010; Shimomura et al. 2011). The varying structural capacity and ductility at transient states of progressive corrosion is under investigation, but the domain of analysis has not come up yet to the full scale buildings and/or infrastructures. The load conditions discussed in the past efforts have been also limited within the static states. At this moment, seismic and fatigue loads coupled with ambient actions are the new target of investigation (Maeshima et al. 2014).

Under this background as stated above, the authors understand that each component technology earned in the past has been partially linked, but not connected consistently throughout the whole scales from micro to macro-levels. The aim of this paper is to portray the possible computational framework throughout the micro (material) and real scale (building) modeling associated with steel corrosion, and to dispel the computational difficulty when executing the simulation for practice. For meeting the challenge, the authors make use of the multi-scale thermo-hygro-mechanics simulation as summarized in the following section.

Here, the chief attention is directed to the computational aspects for several case-studies. Then, the experimental verification especially at the full scale of real buildings is thought to be a future challenge, which is currently discussed in several institutes having large-scale capacity of loading. Computational discussion of this case study is expected to offer some discussing points of real-scale experiments in future. 


\section{Multi-scale integrated analytical system}

Multi-scale integrated system ' $D u C O M-C O M 3$ ' is the platform that couples the thermodynamic simulator with the structural mechanics modeling (Maekawa et al. 2003, 2008). $D u C O M$ is a part to simulate the cement hydration, micro-pore structure development and mass transport of solid and chemical substances in spaces. COM3 encompasses the macroscopic behaviors of structural concrete incorporating the cracks and yield of reinforcement for nonlinear mechanics.

These constituent systems are integrated over the multi-scaling of modeling as summarized in Fig. 1. First, the amount of CSH hydrated gel particles of $10^{-9} \mathrm{~m}$ scale is calculated from the cement hydration rate model in concrete mixture. Then, the micro-pore size distribution is statistically computed based upon the mean space between gel particles. At this stage, by solving the thermodynamic equilibrium of Kelvin, Laplace and Clausius-Clapeyron's equations, saturation of micro-pore spaces with different sizes can be obtained. Second, this statistical information of assembly of micro-pores and their saturation is integrated over $10^{-6} \mathrm{~m}$ scale as shown in Fig. 1. Third, the microscopic motion of moisture is volumetrically integrated into the mass conservation formulae of meso-scale of $10^{-3} \mathrm{~m}$ with variable diffusivity, which can be derived from the microscopic motion of moisture (Maekawa et al. 2003, 2008). Fourth, this mass balance formula is further integrated over the $10^{-0} \mathrm{~m}$ scale again by means of weight residual function method. This quarto-integration over the multi-scales of 3D extent is finally coupled with the cracked constitutive modeling for structural reinforced concrete of $10^{-0 \sim+2} \mathrm{~m}$ scale as shown in Fig. 1.

This linkage is not one-way but mutual. For example, when concrete is subjected to drying, concrete shrinkage and internal stresses and/or cracks are simultaneously computed (Gebreyouhannes et al. 2014a). Newly produced space in between crack planes computationally serves as an additional path of vapor and chloride transport, which may affect the microscopic thermo-dynamic states, and furthermore accelerate the corrosion. Then, the authors apply this holistic approach to this case study.

The corrosion rate, which is computed based upon the moisture content, $\mathrm{pH}$ and the concentration of dissolved oxygen and chloride ions, is shared by the structural sub-system (Toongoenthong and Maekawa 2005) to calculate the internal stresses and cracking in the macroscopic level of finite elements. The experimental verification in use of corroded RC beams in flexural shear has been conducted (Chijiwa et al. 2010, 2011; Toongoenthong and Maekawa 2005) within the framework of COM3 under the forced corrosion rates. In this case study, the applicability will be extended to highly compressed $\mathrm{RC}$ columns subjected to lateral seismic actions in the following section.

In the life-span simulation, permanent loads and am- bient actions have to be applied to the targeted structures before the gigantic short-term seismic actions. Then, the creep and time-dependent progressive propagation of cracks in concrete is also taken into account by using the solidification models of $10^{-3} \mathrm{~m}$ scale (Asamoto et al. 2006). Necessary and sufficient time-step intervals for long-term simulation (about $10^{5} \mathrm{sec}$ ) and that for short-term dynamic actions (about $10^{-2} \mathrm{sec}$ ) greatly differ. If the time step would be drastically changed in the time sequence of structural life from $10^{5} \mathrm{sec}$ to $10^{-2} \mathrm{sec}$, round error may be accumulated in numerical integration with respect to time and may cause crash of numerical integration. Then, the re-start of sequential jobs or the logarithmic time integration algorithm (Maekawa et al. 2006) is practically proposed to avoid the accumulated round error of the digital processing.

As the huge degree of freedom (DOF) has to be handled with large in-core memory assignment needed, the parallel computation is applied for spatially divided finite element domains in each chemo-physical event (solid formation with moisture migration, oxygen migration with steel corrosion, chloride migration with dissolution-adsorption equilibrium, dioxide migration with carbonation and momentum equilibrium with solid nonlinearity via damaging and plasticity). Although the multi-chemo-mechanistic computation is sequentially arranged in global solution, the common memory space throughout the whole events is assigned inside the direct accessible memory from each parallel CPU.

\section{Verification: Seismic resistance of RC columns exposed to marine environment}

The stand-alone system of COM3 was experimentally verified by using the data of corroded $\mathrm{RC}$ beams in shear. When the unsaturated state in micro-pores develops, the corrosion gel is computationally assumed to be firmly formed around the surface of mother steel bars (Wong et al. 2010, Chijiwa et al. 2011). On the other hand, migration of corrosion gel into cracks may be possibly considered under submerged conditions of full saturation (Toongoenthong and Maekawa 2005; Gebreyouhannes et al. 2014b; Takaya et al. 2013). In this case study, the authors take over this framework of corrosion gel formation, and inter-linked with $\mathrm{DuCOM}$ sub-system through the generation rate of corrosion gel as a commonly shared variable in both sub-systems as shown in Fig. 1.

For verification, the degraded seismic performances of heavily corroded columns (Arasato et al. 2003), which were located close to a coastal line of Okinawa Prefecture for a long time, is simulated. Okinawa is the deepest south in the semi-tropical region of Japan. Here, strong wind with much airborne chloride blows periodically, especially when a typhoon comes. The column specimens as a mockup of building members were exposed to such an environment for 4 years. After the exposure, alternate loading tests were conducted under highly axial compression. 


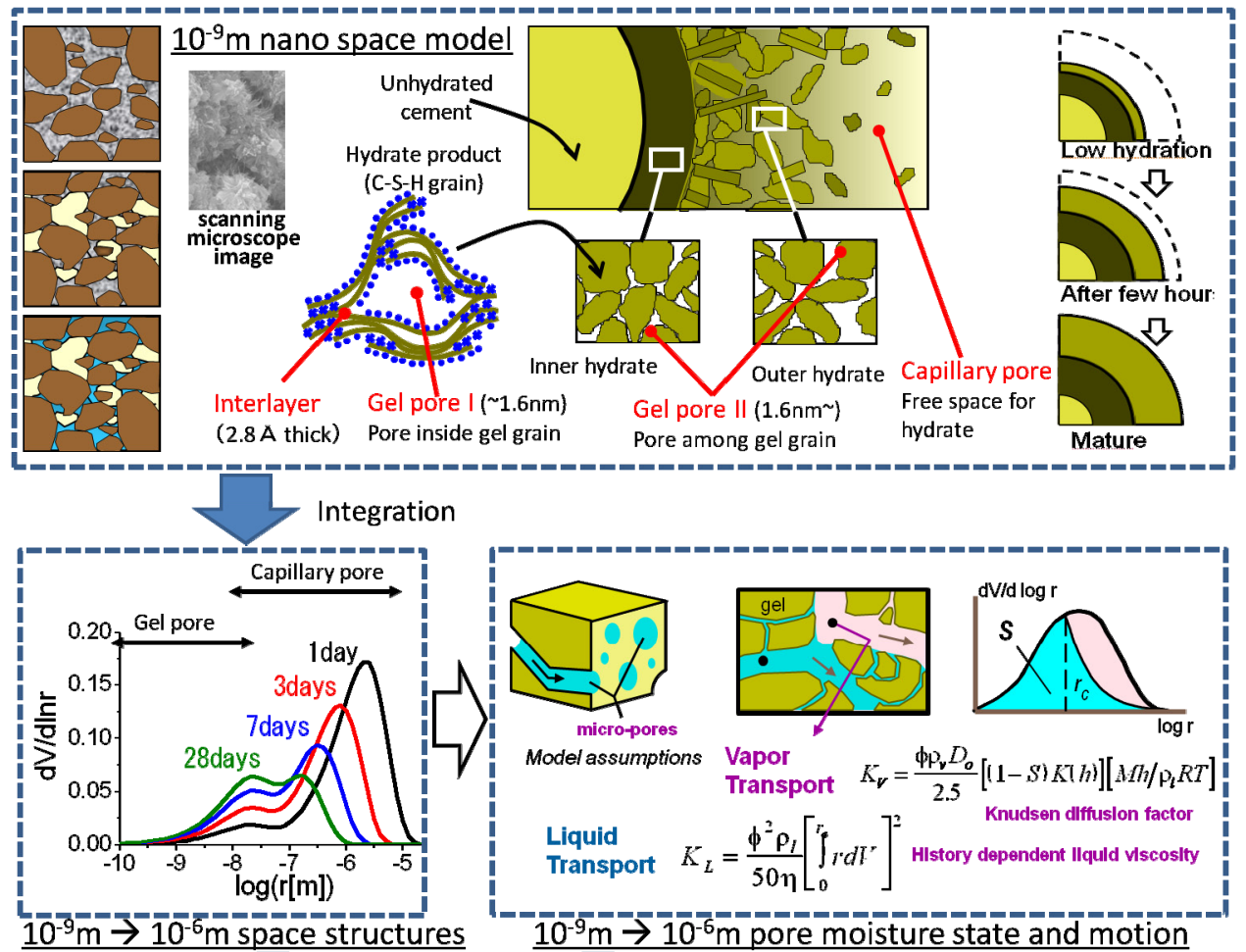

$\underline{10^{-9} \mathrm{~m} \rightarrow} 10^{-6} \mathrm{~m}$ space structures $\quad 10^{-9} \mathrm{~m} \rightarrow 10^{-6} \mathrm{~m}$ pore moisture state and motion

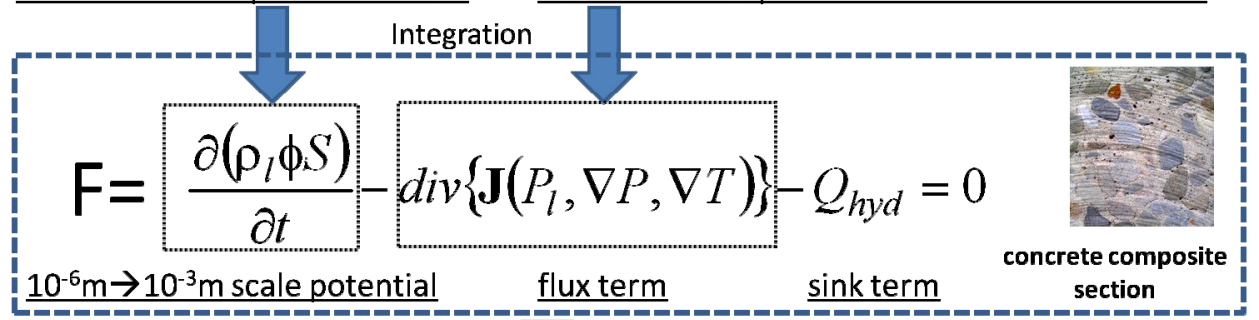

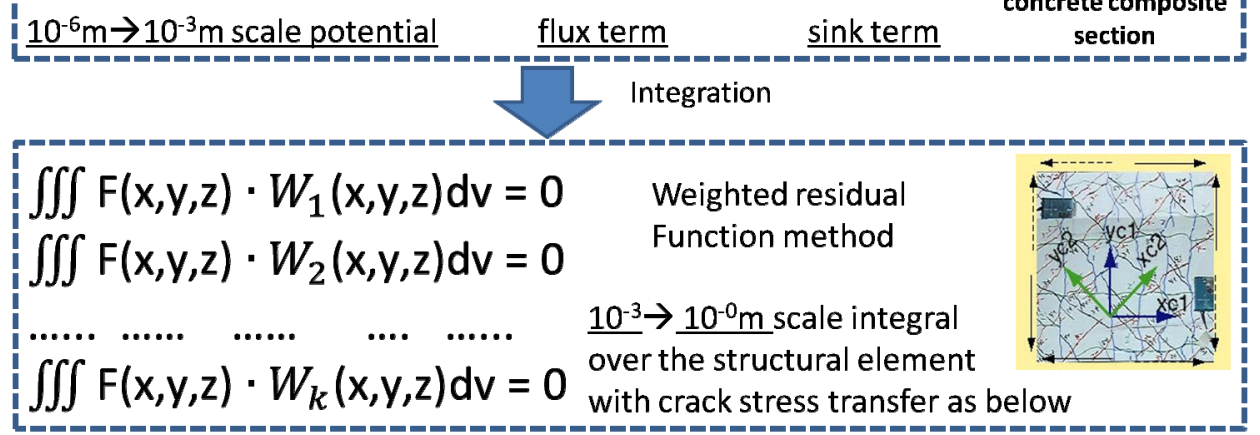

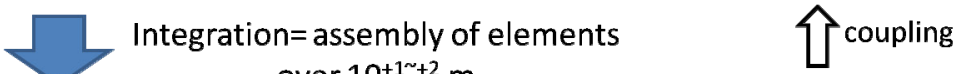

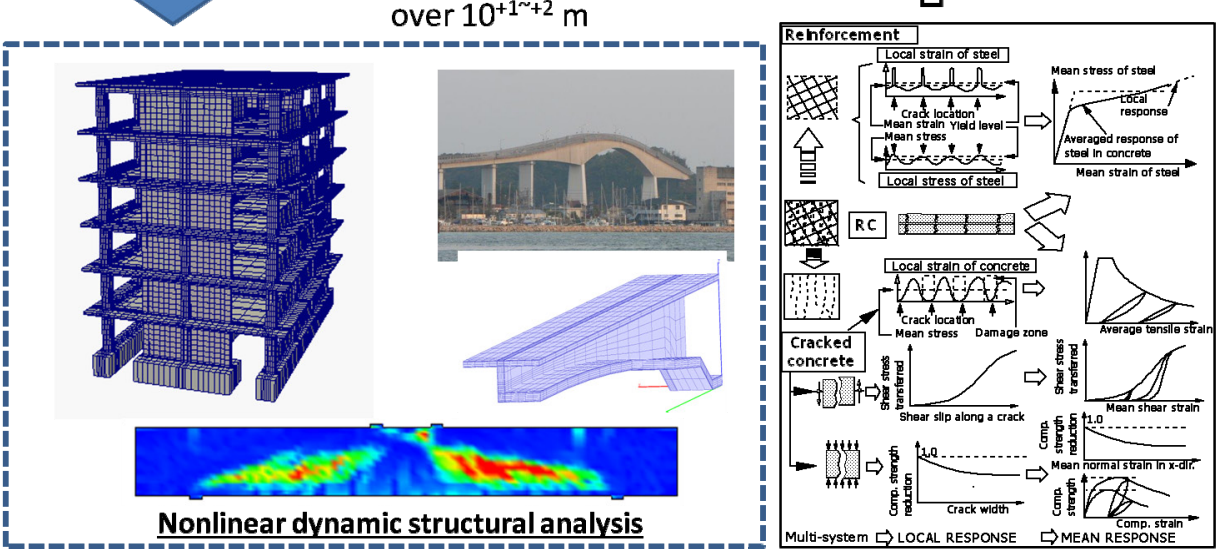

Fig. 1 Scheme of the multi-scale thermo-hygro-mechanical analytical platform - allow means the integral with respect to the 3D space over the scale - (Maekawa et al. 2008; Gebreyouhannes et al. 2014a). 
Figure 2 shows the exposure site (Funaki et al. 2008) and the finite element discretization for the target member. In consideration of the symmetry of both geometry and loading patterns, one half of the member is computed. For keeping the top and the bottom surfaces in parallel, so called pantographic system of loading was used in the experiment. With the same manner as that shown in Fig. 2, lineal truss elements which can bear just axial forces with high rigidity are attached to the specimen so that the top and bottom planes are numerically kept horizontal without any constraint to the axial force as well. The ambient data of air temperature, relative humidity and the concentration airborne chloride is not available at the exact exposure site. Then, the authors refer to the meteorological data at Naha city in Okinawa and used the annual average temperature as constant in the analysis (see Table 1). As the airborne chloride is not available at the site too, the chloride ion concentration in pore solution was estimated at the surface of the column based upon directly measured chloride profile inside the specimen (Arasato et al. 2003). The wet and dry cycle is known to advance the penetration of chloride. Here, a daily fluctuation of the relative humidity is assumed to idealize the ambient states close to the exposure site where splashing sea water comes every day. Table $\mathbf{1}$ summarizes the specified ambient boundary conditions used in this case study.

Figure 3 shows a comparison of the experiments and the analyses. For the un-corroded specimens, the analytical result captures the overall ductility and capacity. Here, the vertical mean strain denoted by $\varepsilon_{\mathrm{v}}$ serves as an
Table 1 Assumed simple environmental data.

\begin{tabular}{|c|c|}
\hline Temperature & $23.1^{\circ} \mathrm{C}$ \\
\hline Relative humidity: $\mathrm{RH}$ & $\begin{array}{c}60 \sim 99.9 \% \\
\text { (wet \& dry cyclic per day) }\end{array}$ \\
\hline Initial concentration of $\mathrm{O}_{2}$ & $9.3 \times 10-6 \mathrm{~mol} / l$ \\
\hline $\begin{array}{c}\text { Concentration of } \mathrm{O}_{2} \\
\text { in the surface of concrete }\end{array}$ & $9.3 \times 10-6 \mathrm{~mol} / l$ \\
\hline $\begin{array}{c}\text { Concentration of } \mathrm{Cl}- \\
\text { on the surface of } \\
\text { concrete }\end{array}$ & $\begin{array}{c}0 \sim 2.36 \mathrm{~g} / l \\
\text { (Lineally increased for 4years } \\
\text { from exposure) }\end{array}$ \\
\hline
\end{tabular}

stability indicator of columns. The vertical mean strain in progress of compression side means that the column may hardly bear axial compression steadily. As this specimen was subjected to high axial compression, the compressive strength of concrete is rather sensitive to the member behaviors. In this analysis, the compressive strength is not the input value but the computed one in accordance with the microstructure development of cement matrix. The computed compressive strength, which corresponds to the analytically specified water to cement ratio of $50 \%$, is almost the same as the tested one.

For the corroded specimens, the simulated R-V and $\mathrm{R}-\varepsilon_{\mathrm{v}}$ relations substantially match with the experiment. It can be observed in Fig. 3 that both the maximum load and the initial stiffness are reduced owing to the corrosion in both experiment and analysis. The failure mode shifts from flexure to the flexural-shear failure due to corrosion. The analysis may capture the localized shear band with less inclination against the member axis. This is attributed to the high axial compression $(20 \%$ of the

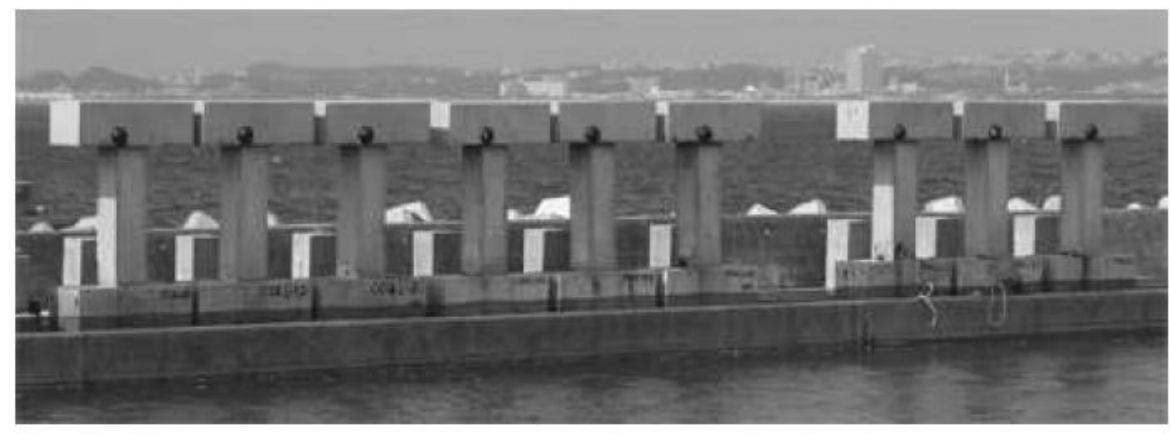

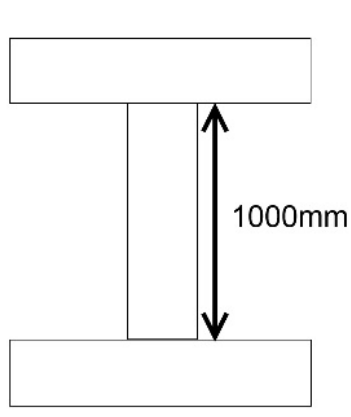

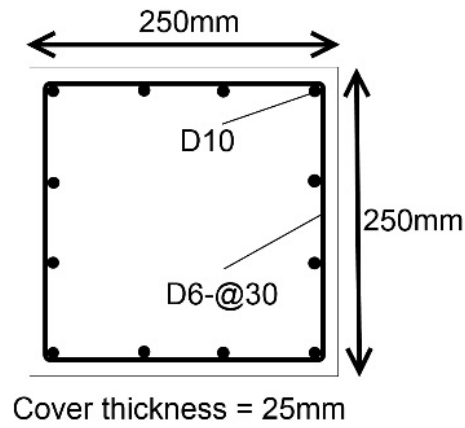

$\mathrm{W} / \mathrm{C}=50 \%$

Yield strength of the steel $=400 \mathrm{MPa}$

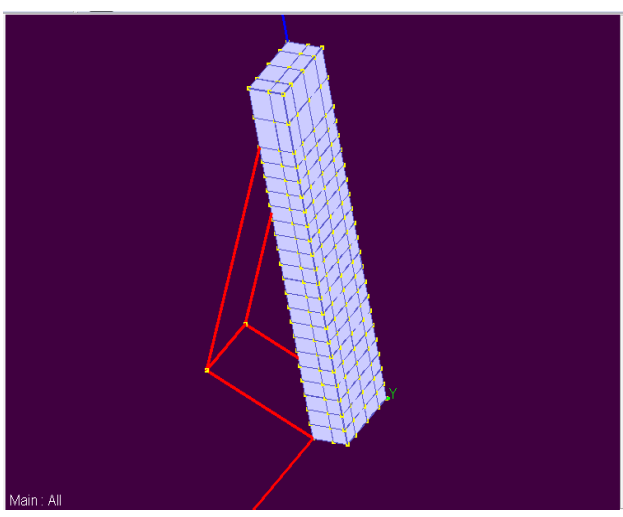

Fig. 2. Section details of the specimen (Funaki et al. 2008) and FE mesh with pantographic system. 

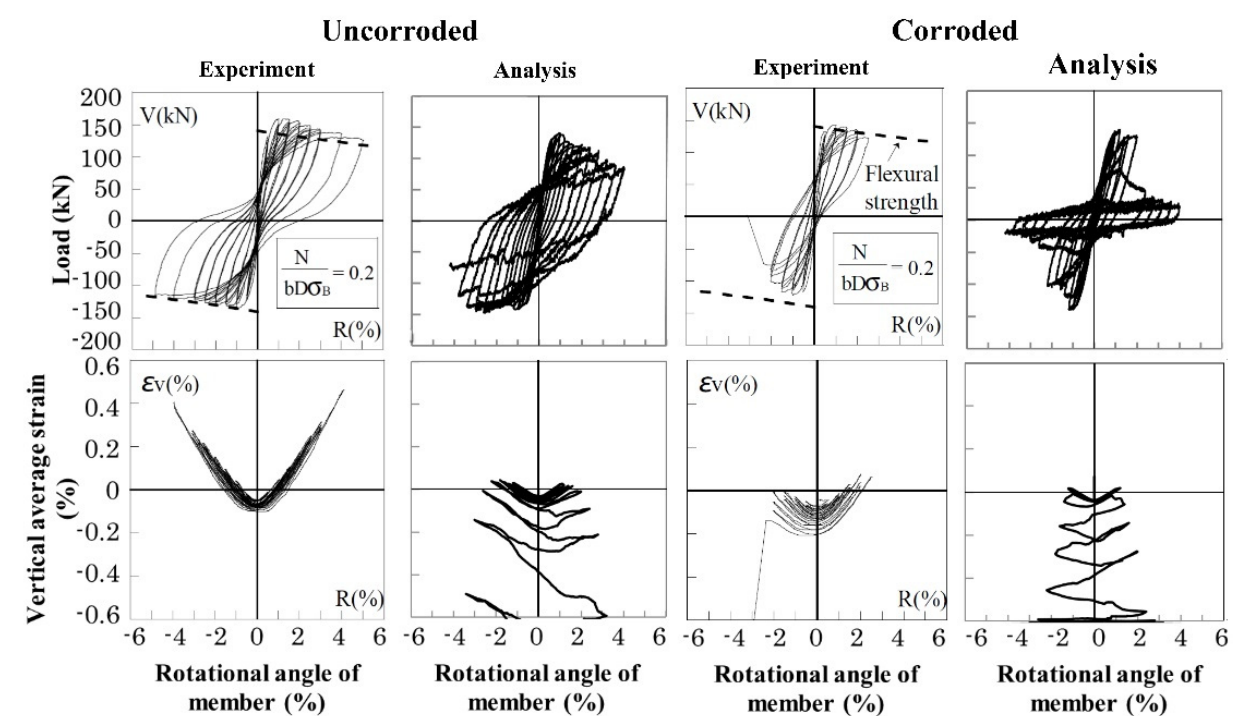

Fig. 3 Comparison of $\mathrm{R}-\mathrm{V}$ and $\mathrm{R}-\varepsilon v$ relations between experiment and analysis.

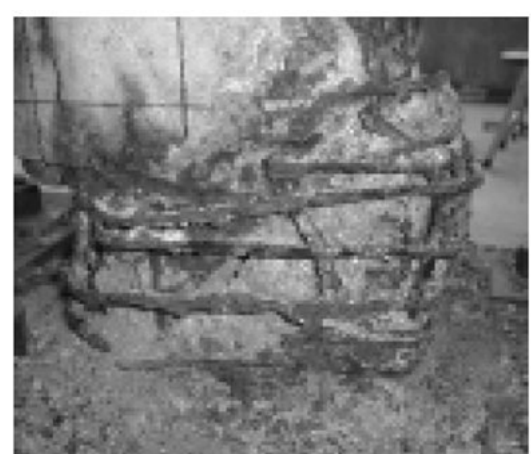

(a) Experiment (Arasato et al. 2003)

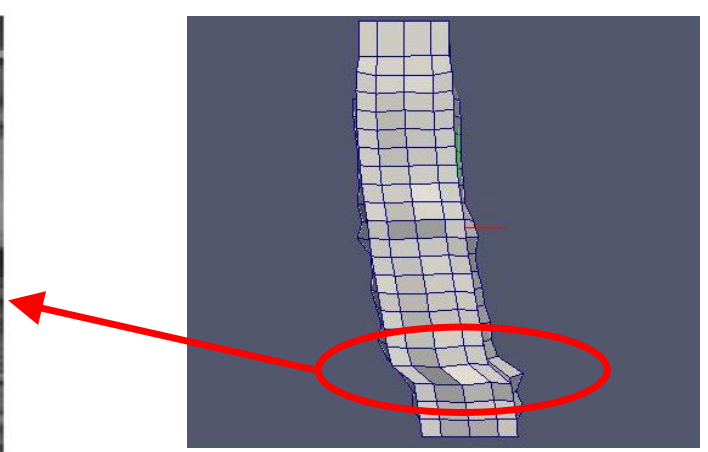

(b) Analysis

Fig. 4 Comparison of the failure mode.

\section{Experimental result}

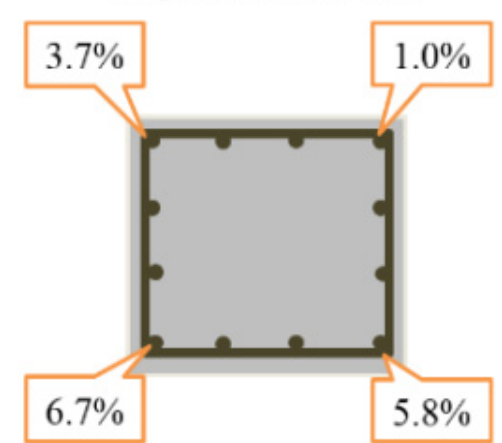

Analytical result

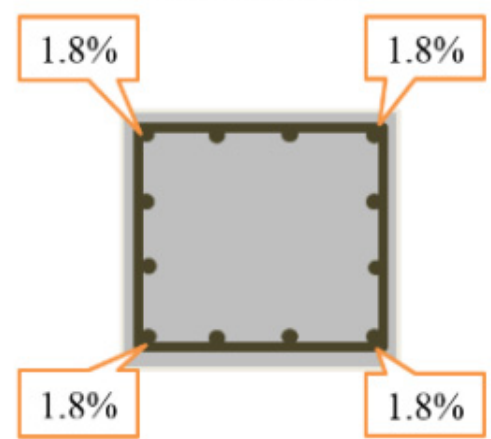

Fig. 5 Comparison of the mass loss of the main bars between experiment and analysis.

pure axial compressive capacity). Analysis may also reproduce the progressive compressive deformation in the vertical direction which was observed in the experiment (Arasato et al. 2003) by the combined effect of corrosion and the high axial force (see Fig. 4).

The steel corrosion around the reinforcing bars was found not to be uniform in the experiment; some cross-sections have more than $20 \%$ mass loss of reinforcing bars, while the average mass loss in the whole reinforcing bars is $5 \%$. This variability is thought to derive from the local climates of large deviation. By coastal lines, complexity of wind direction, washing out of chloride by rainfall and the direction of sunshine may create un-uniform micro-environmental conditions. The simulated corrosion distribution of the bars under the estimated uniform chloride ion concentration naturally leads to the uniformity unlike the reality. The absolute computed mass loss inevitably differs from the experiments (see Fig. 5) but the order is consistent.

The concrete cover is seriously damaged in the 
analysis and more or less macroscopic bond between concrete and reinforcement are almost lost (Chijiwa et al. 2010, 2011). Then, the computed seismic performance is not so different from that in Figs. $\mathbf{3}$ and $\mathbf{4}$ even if more corrosion would be induced to the target member. Then, the authors use this computed corrosion magnitude and the boundary conditions for further structural performance simulation as follows.

\section{Sensitivity analysis on RC column members}

\section{(1) Column without shear reinforcement}

For clarify the impact of corrosion on the column mechanics, sensitivity analysis is conducted in this section based upon the simulator examined in the previous section. First, the structural performance of corroded RC columns without web reinforcement is discussed. The detailed dimensioning and its FE mesh are shown in Fig. 6. The same boundary condition is applied as in the previous section. The thermodynamic environmental condition is assumed simply as 40 degree Celsius and 60\% relative humidity. Two cases of the chloride ion concentration assumed in the mixing water are $6.1 \mathrm{~g} / l$ and $12.2 \mathrm{~g} / \mathrm{l}$, respectively. The airborne chloride ion is not

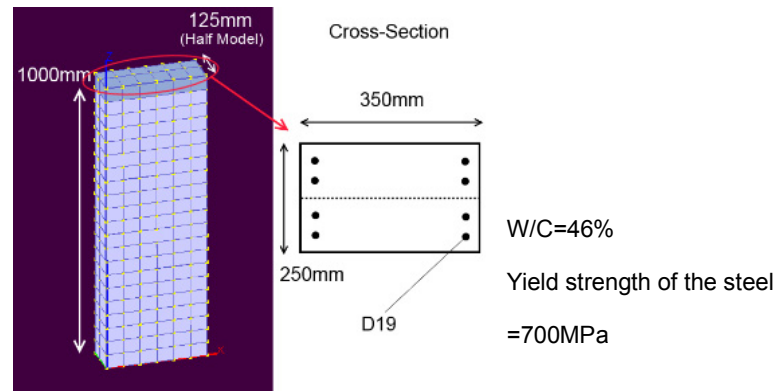

Fig. 6 RC column model without shear reinforcement.
Table 2 Assumed environmental data in the analysis of the column without shear reinforcement.

\begin{tabular}{|c|c|}
\hline Temperature & $40.0^{\circ} \mathrm{C}$ \\
\hline $\mathrm{RH}$ & $60 \%$ \\
\hline Initial concentration of $\mathrm{O}_{2}$ & $9.3 \times 10-6 \mathrm{~mol} / l$ \\
\hline $\begin{array}{c}\text { Concentration of } \mathrm{O}_{2} \\
\text { in the surface of concrete }\end{array}$ & $9.3 \times 10-6 \mathrm{~mol} / l$ \\
\hline $\begin{array}{c}\text { Concentration of } \mathrm{Cl}^{-} \\
\text {in the surface of concrete }\end{array}$ & $6.1 \mathrm{~g} / l$ or $12.2 \mathrm{~g} / l$ \\
\hline
\end{tabular}

Table 3 Assumed environmental data in the analysis of the column with shear reinforcement.

\begin{tabular}{|c|c|}
\hline Temperature & $40.0^{\circ} \mathrm{C}$ \\
\hline $\mathrm{RH}$ & $60 \%$ \\
\hline Initial concentration of $\mathrm{O}_{2}$ & $9.3 \times 10-6 \mathrm{~mol} / l$ \\
\hline $\begin{array}{c}\text { Concentration of } \mathrm{O}_{2} \\
\text { in the surface of concrete }\end{array}$ & $9.3 \times 10-6 \mathrm{~mol} / l$ \\
\hline $\begin{array}{c}\text { Concentration of } \mathrm{Cl}^{-} \\
\text {in the surface of concrete }\end{array}$ & $6.1 \mathrm{~g} / l$ \\
\hline
\end{tabular}

considered in this sensitivity analysis. The applied ambient boundary conditions are summarized in Table 2 .

Figure 7 shows the varying load-deflection curves with the periods exposed to the assumed ambient conditions. While the column fails in shear after the yield of main reinforcing bars at an early stage of corrosion, the column computationally fails in shear before the yield of steel at a progressed stage of corrosion, where the ductility is much decayed as well. Figure $\mathbf{8}$ is the computed relation of the age of material and the load bearing capacity. This result shows that the rate of deterioration is governed by the initial chloride ion concentration.

Figure 9 shows the relation of the load carrying capacity and the corrosion rate of main reinforcement. The line on the graph expressed the calculated shear capacity calculated computed by the JSCE design formula (2012). In this calculation of the codified formulae, only the mass

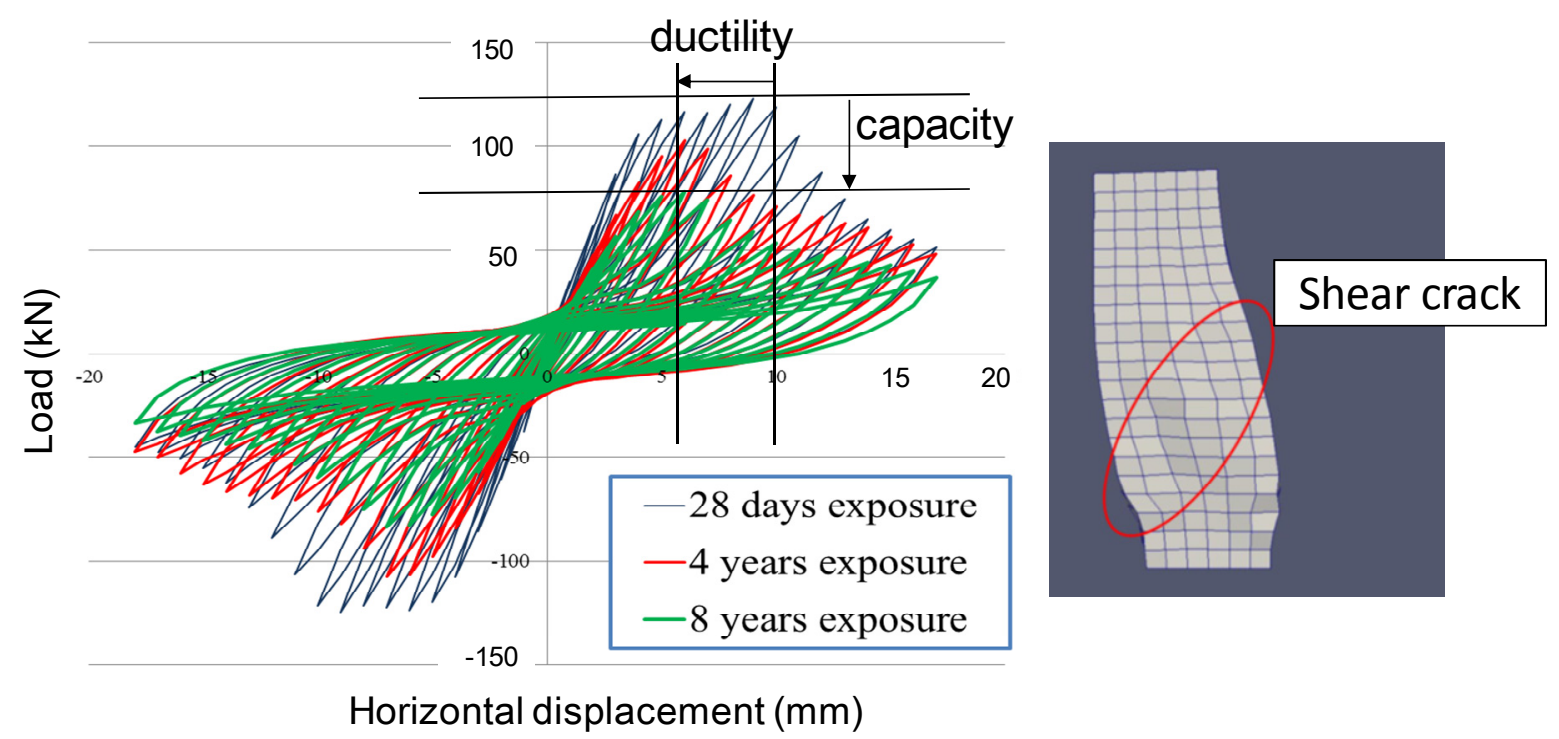

Fig. 7 Varying load-deflection curves with corrosion. 


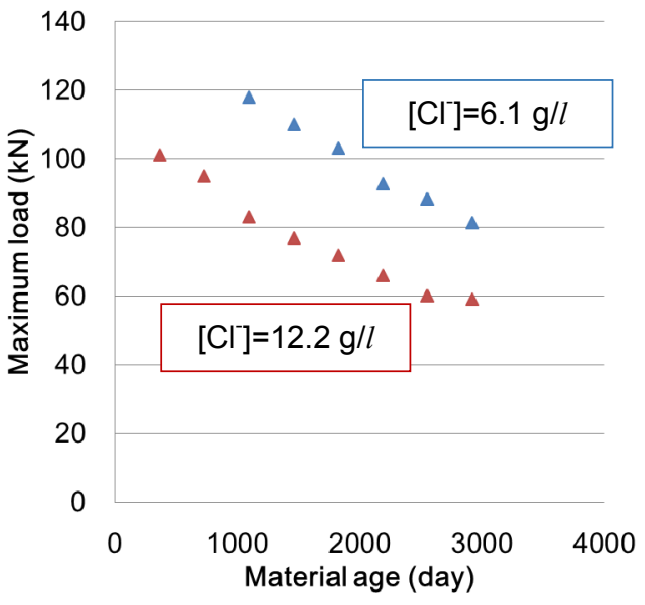

Fig. 8 The relations of the age of material and the maximum load.

loss of the reinforcing bars is considered in terms of the reduced reinforcement ratio. Of course, the effect of corrosion cracking along the main reinforcement cannot be taken into account by this empirical formula. The result shows that the reduction of the shear capacity simulated by the multi-scale analysis is much larger than that by the JSCE formula (2012) for shear.

It implied that corrosion cracking has larger influence on the deterioration of structural performance by steel corrosion than the mere section loss of the reinforcing bars. The arm length between the centroids of flexural compression and tension is changed by the corrosion cracking along the main bars. At the same time, the macroscopic bond between main reinforcement and the web concrete is much deteriorated, because the web and tension cords are mechanically detached by the corrosion cracking parallel to the main bars. Here, the FE analyzed shear capacity of the non-corroded RC beam is about $30 \%$ reasonably higher than the calculation by the JSCE formula (2012) which estimates the initiation of a diagonal shear cracking. As a matter of fact, the shear collapsing capacity, which is computed by the numerical model in this section, is known to be $20 \sim 30 \%$ greater than the load which brings about the first diagonal cracking for shear to span ratio is around 3.

\section{(2) Column with shear reinforcement}

The details of the target column in this section are the same as those discussed in the previous section (Arasato et al. 2003). The assumed ambient condition in this sensitivity analysis is 40 degrees Celsius as constant and the daily fluctuation of $60-99.9 \%$ relative humidity. Air borne chloride ion is set to be $2.36 \mathrm{~g} / l$ as constant. In order to clarify the effect of location where the corrosion occurs, first, we set up the severer corrosive environments as stated above and the second, two cases are assumed; one is the corrosion which is allowed to occur only on the main reinforcing bars similar to the previous section, and the other is the corrosion solely on web reinforcing bars. After 4 or 8 years exposure, the column is numerically loaded alternatively in the horizontal

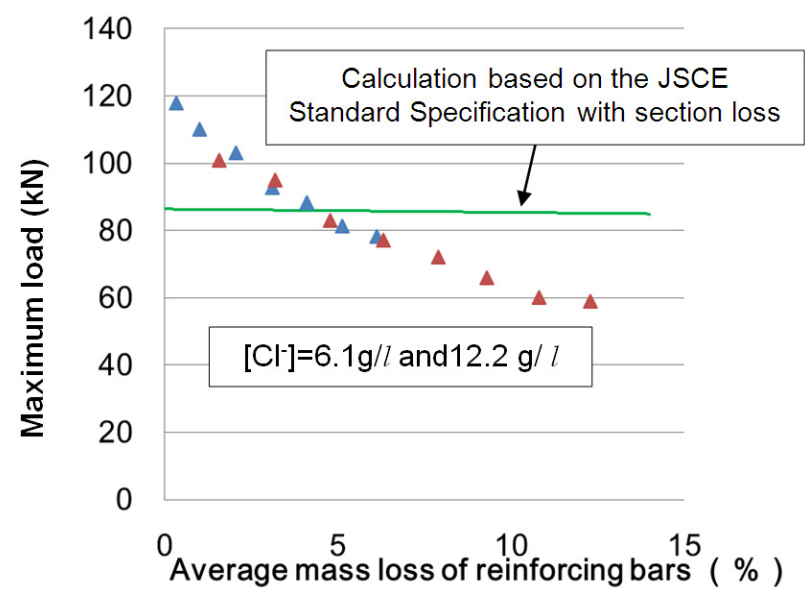

Fig. 9 The relation of the average mass loss of main reinforcement and the load bearing capacity in shear.

direction under high vertical load.

The analytical result is shown in Fig. 10. From the comparison of two extreme cases, cracks along web reinforcement cause greater decrease in the horizontal member stiffness and ductility compared to the case of corrosion solely in the main reinforcement. It is understood that the flexural arm length between the centroids of flexural compression and the tension reinforcement becomes shortened owing to the cover concrete damage caused by the corrosion around the web reinforcement. As a matter of fact, the residual capacity is degraded according to the magnitude of corrosion ( 4 and 8 years), but the axial load carrying mechanism remains undamaged and no compressive strain along the axis of the column is seen (see Fig. 10). In fact, no clear shear deformation is reproduced. The corrosion of web reinforcement may bring about decay of flexural performance but the abrupt propagation of diagonal shear cracks is suppressed.

On the contrary, we can see less reduction of the member stiffness under the small number of reversed cycles, and there is no substantial difference between 4 and 8 years corrosion unlike the case of corroded web reinforcement. However, the rapid decay of load carrying mechanism can be seen after some numbers of cycles. This may attribute to the macroscopic bond loss caused by the cracking along the main reinforcement. Then, the axial load carrying mechanism is gradually lost in accordance with the horizontal drift.

\section{Thermo-hygral analysis of full scale RC building}

Structural system composed of RC beams, columns and walls has large degree of redundancy. In such a system, the effect of steel corrosion on the global system may differ from that of constituent structural components. As a matter of fact, corrosion of reinforcement may change the stiffness which affects the whole structural dynamic responses as well as the ductility and capacity of the local components. Then, for the risk assessment of the pro- 


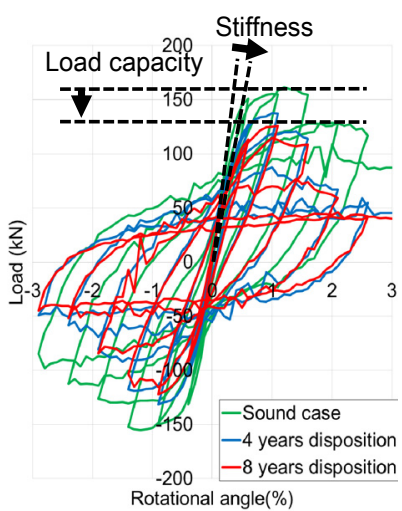

Corrosion on main reinforcement
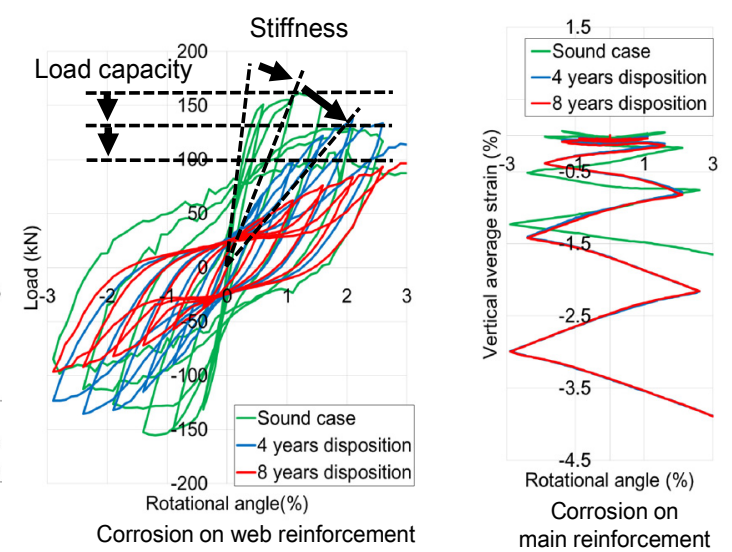

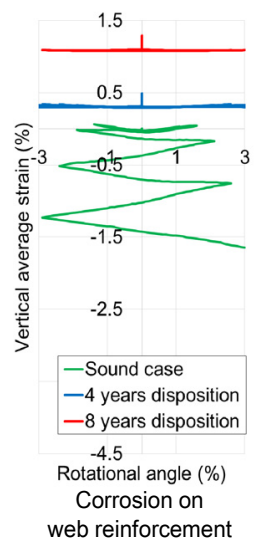

web reinforcement

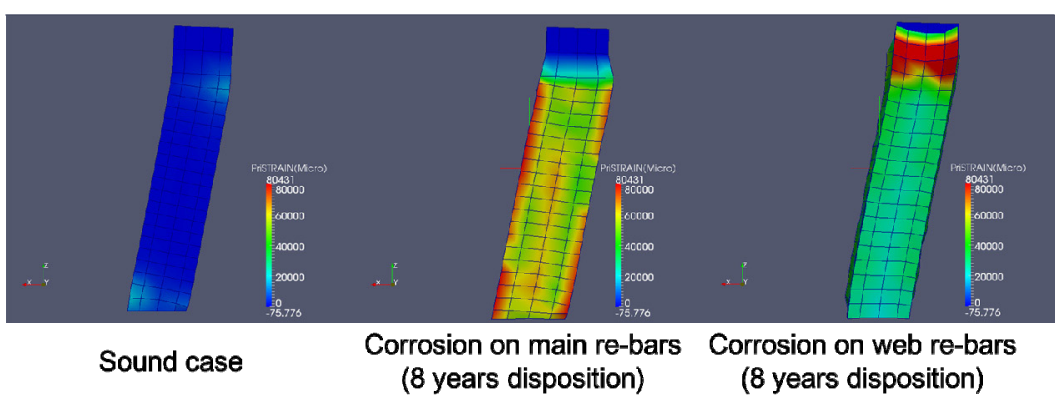

Fig. 10 Simulated cyclic responses of corroded RC columns.

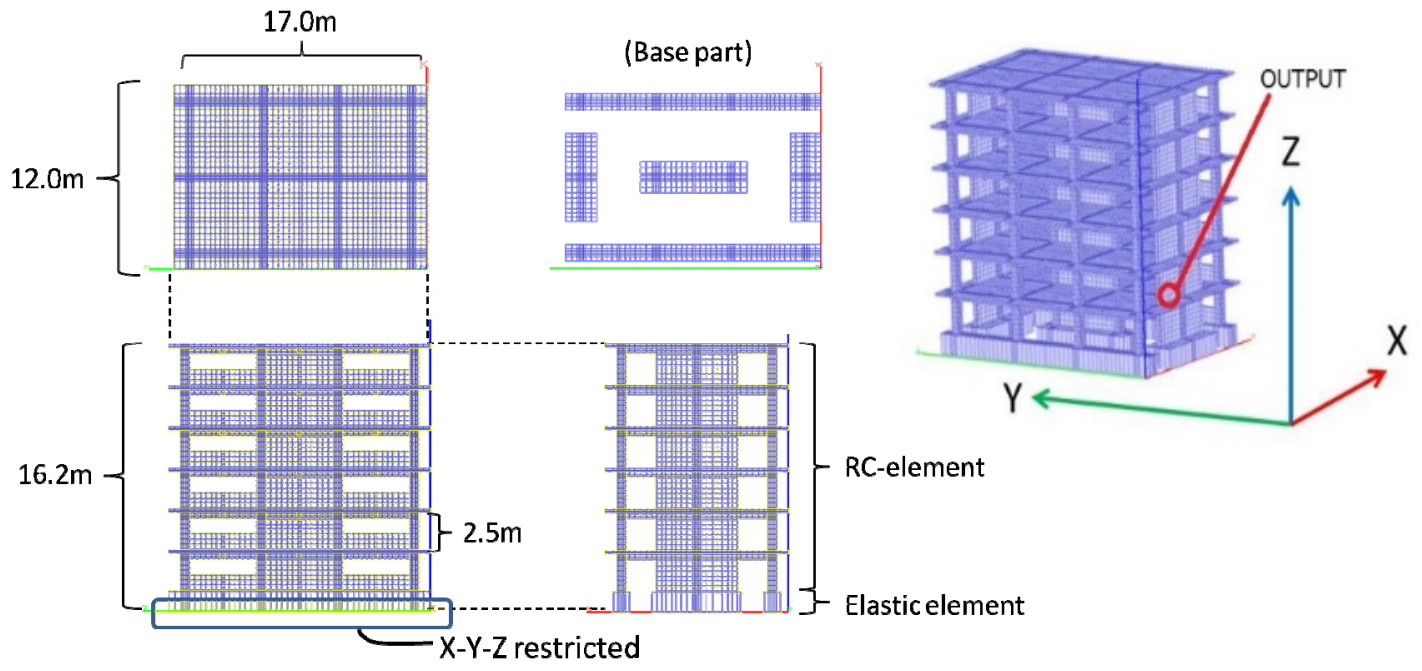

Fig. 11 The FE mesh and the output point of floor drift.

gressive collapse (Izzuddin et al. 2008; Abruzzo at al. 2006) of corroded buildings, the multi-chemo-physics modeling is expected to serve in line with the safety assessment of existing buildings.

\section{(1) Effect of drying shrinkage}

A reference case should be specified for discussion on the corrosion impact. The authors first selected the target whose structural detailing, material used and its seismic responses are known by experiments. It is the real-scale six-story RC building of which seismic response above the shaking table was reported (Matsumori et al. 2008). The test was conducted at E-defense of Hyogo Earthquake Engineering Research Center. The total weight of the mockup building is about 1,000 tonf, and it has 12 columns in each floor. The input seismic wave was the ground motion recorded at Kobe Great Earthquake in 1995, whose maximum acceleration is 818 gal. In the experiment, the wave amplitude was increased step by step as $5 \%, 10 \%, 25 \%, 50 \%$ and $100 \%$ of the original. The mockup was firmly fixed to the shaking table. Then, the soil-structure interaction is neglected for simplicity. A finite element mesh is made in accordance with the dimensioning and detailing of the real scale building as shown in Fig. 11.

In this case study, two series of seismic analyses are conducted. One is the stand-alone run by COM3 in which the tested value of the compressive strength of concrete 
is used as a material property. Here, the reduced tensile strength of concrete is also defined to equivalently reflect the effect of drying shrinkage, because thin walls and floor slabs confined by the beam-column frames are subjected to initial stresses (Maekawa et al. 2008). Another one is the multi-scale analysis in which the solid formation and the effect of drying shrinkage are automatically taken into account in the process of hydration and moisture migration though the whole volume of structures. Here, it is not necessary to use the tested material strength of concrete which are to be computed in the multi-scale process of solid formation (Maekawa et al. 2008). In the experiment, some cracks were found before the dynamic loading (Fig. 13a). Then, the drying shrinkage is obvious.

Figure 12 shows the comparison of the experiment and stand-alone analysis on the drift response of the second floor. Coordinate (X-Y) defines the horizontal plane parallel to the floor and coordinate $\mathrm{Z}$ indicates the vertical axis. The motion of the building can be roughly reproduced. In this case, the reduced tensile strength by $40 \%$ was defined according to the past experiences for shear and flexure analyses. In using the simplified dynamic frame analysis, the initial stiffness is usually reduced about $20 \%$ for practice.

As for the multi-scale chemo-hygro simulation, two different ambient conditions are challenged. One is the case where the structure is computationally cured under the sealed condition to avoid moisture drying, and the other is that the structure is kept for 21 days under the drying ambient state ( $60 \%$ relative humidity) after 7 days sealed curing. The input wave amplitude is increased step-by-step as $10 \%, 25 \%, 50 \%$ and $100 \%$. Figure 13b shows the comparison of the floor drift of the second floor in the horizontal (X-Y) directions. In each amplitude, the horizontal drift of the case without drying shrinkage is much less than that with the drying. The volumetric shrinkage by drying or self-desiccation may

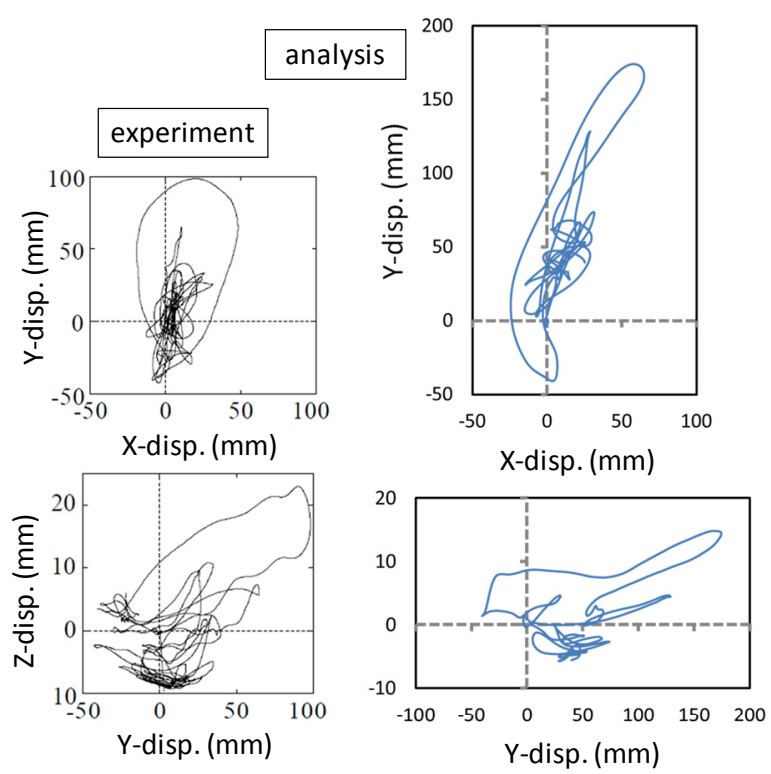

Fig. 12 Floor response in horizontal plane $(x, y)$ and vertical uplift $(x, z)$.

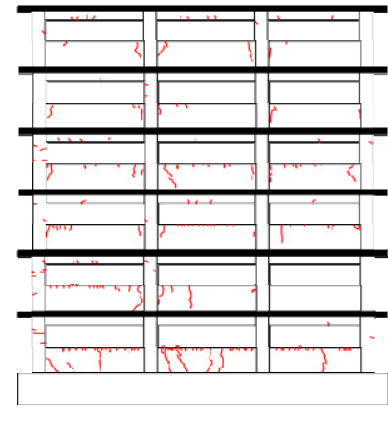

(a) Observed shrinkage cracks in the experiment

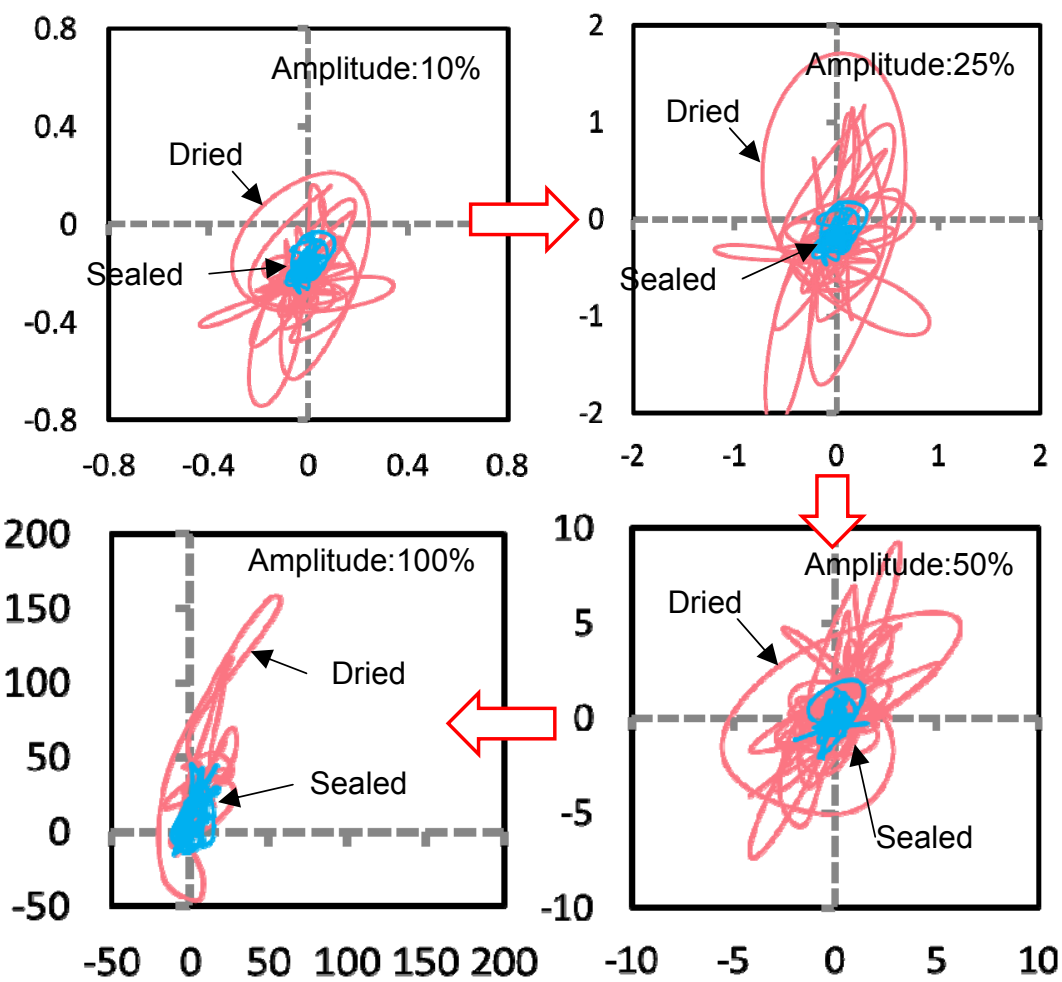

(b) Displacement of $2^{\text {nd }}$ floor in horizontal direction(X-Y)

Fig. 13 Effect of the drying shrinkage on the seismic response. 

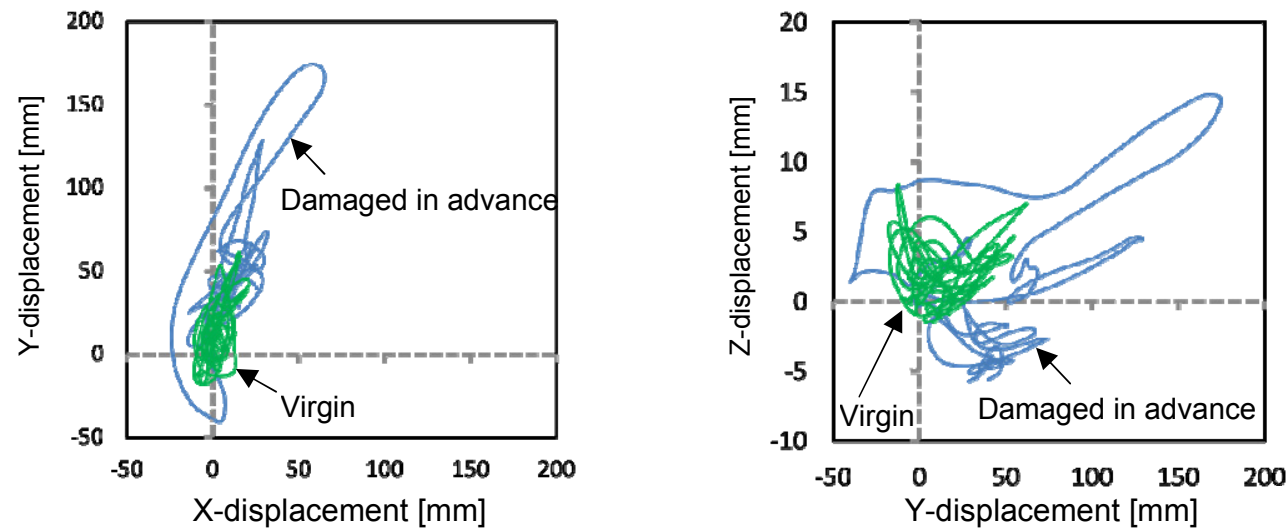

Fig. 14 Effect of the past loading history on the seismic response.

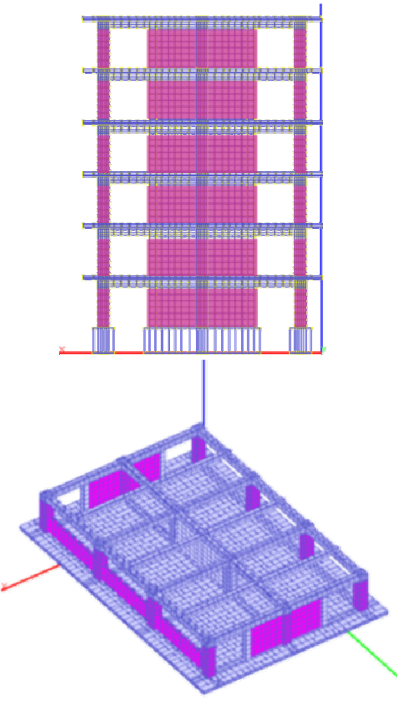

(a) Assumed corroded parts
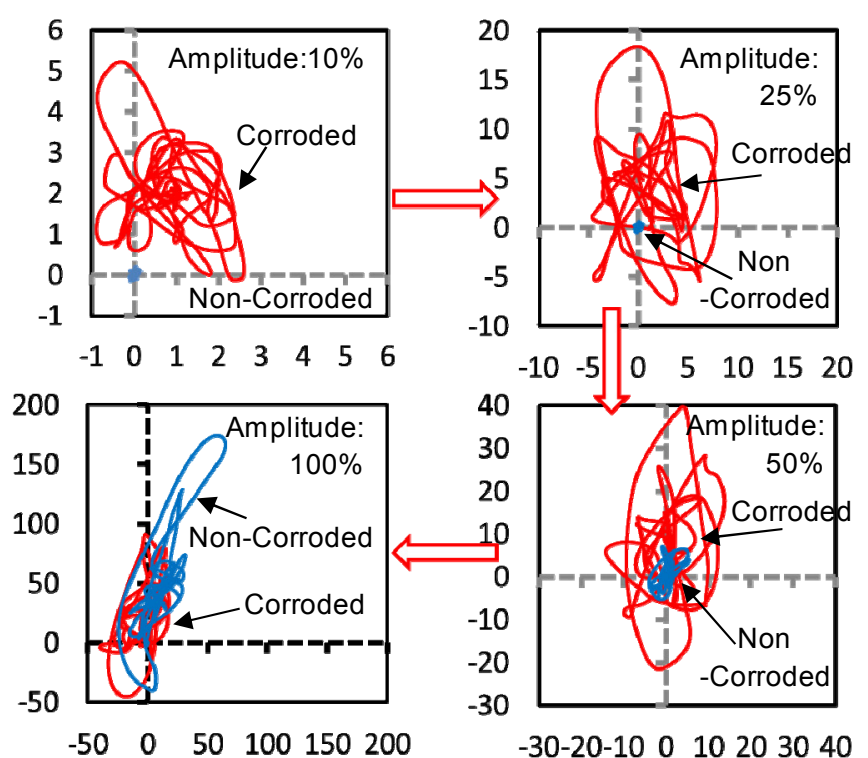

(b) Displacement of $2^{\text {"1 }}$ floor in horizontal direction(X-Y)

Fig. 15 Effect of the corrosion at all stories on the seismic response.

cause self-equilibrated stresses and cracking which results in early cracking when external forces are applied. The multi-scale simulation used in this case study has been verified for computing the shear capacity of RC members (Gebreyouhannes and Maekawa 2011).

The effect of the damage history on the seismic behavior of the building is also analyzed. Two analytical cases are prepared: one case is that the input wave amplitude of the Kobe earthquake is increased in stages as $10 \%, 25 \%, 50 \%$ and $100 \%$, and the other is that the input wave amplitude is just only $100 \%$. Figure 14 shows the comparison of the seismic responses under $100 \%$ seismic amplitude in both cases. It is found that the seismic response is strongly influenced by the past ambient states for the referential case. From Fig. 14, it is found that the structure sinks into $\mathrm{Z}$ direction when the structure has the past damage. As some reinforcing bars have yielded under the past seismic motion, the bottom parts of the columns can be easily crashed, and the floor sinks down. It means that the local carrying mechanism against the gravity is disappearing.

\section{(2) Effect of coupled drying and corrosion}

To clarify the effect of corrosion, the seismic response of the corroded structure with concrete shrinkage is computed and compared with the non-corroded case. It should be noted again that corrosion in the air always accompanies drying shrinkage. This simulation assumes that the columns and walls on the outside of each floor are corroded, and the mass loss of their reinforcing bars is $30 \%$. This assumption may correspond to the case where the building has been in service for decades in a very harsh environment. The same ground motion is used as that of the previous section, and its amplitude is step-by-step magnified as $10 \%, 25 \%, 50 \%$ and $100 \%$.

Figure 15 shows the comparison of the horizontal drift of the second floor with and without corrosion. When the amplitude of ground acceleration is rather small, the drift of the corroded building is large. On the contrary, when the amplitude comes up to $100 \%$, the drift of the non-corroded one is larger than the corroded. Figure 16 shows the drift of each floor in the horizontal Y direction when the drift of the top floor reaches the maximum. The 

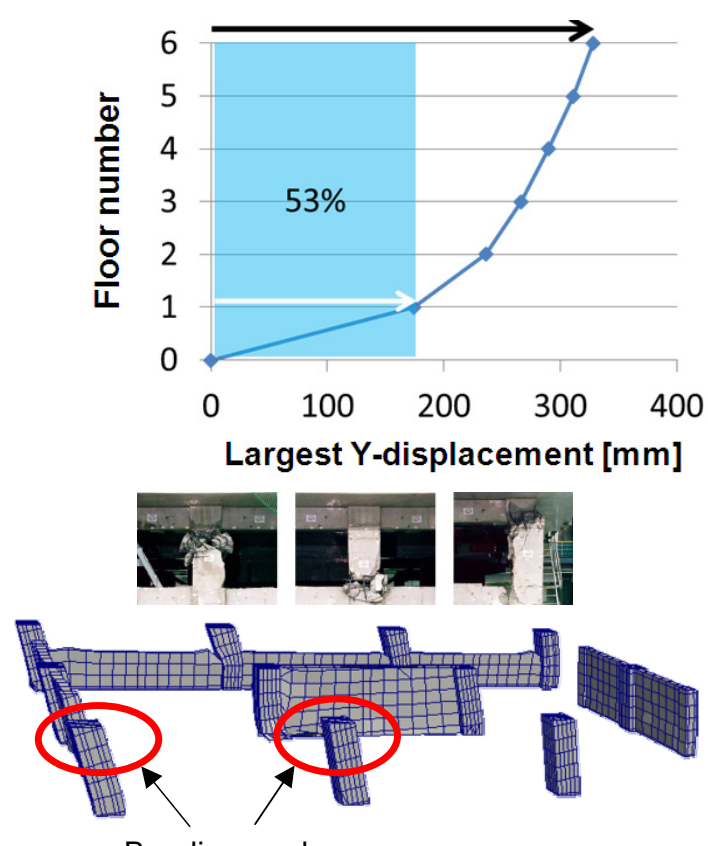

Bending mode

(a)Non-corroded case
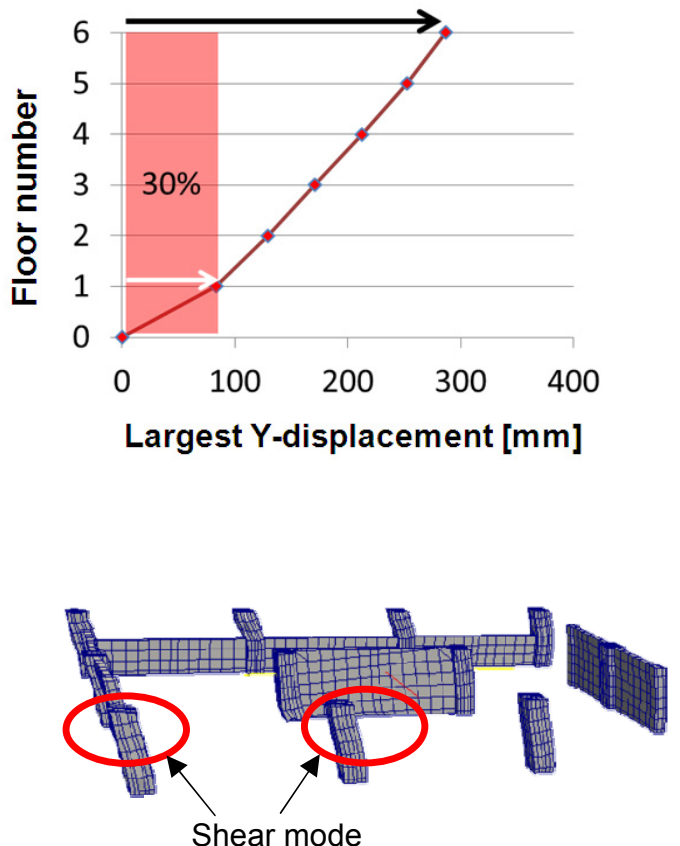

(b)Corroded case

Fig. 16 The floor response diagrams and the mode of failure at the time when the displacement of the top floor reaches the maximum.

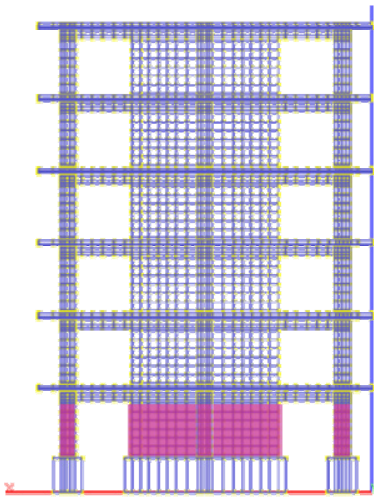

(a) Assumed corroded parts: only the column of ground floor is corroded.

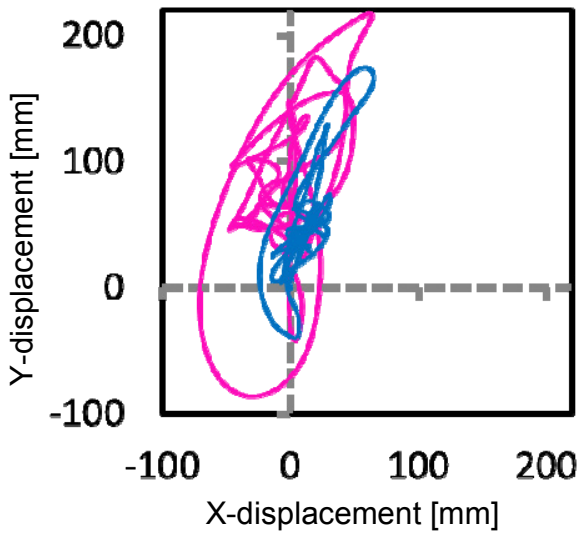

(b) Displacement of 2nd floor in horizontal direction $(X-Y)$

Fig. 17 The effect of the corrosion on the columns of the only ground floor.

horizontal displacement response of the $1^{\text {st }}$ floor in the non-corroded case is almost a half (53\%) of the top one. It is larger than the case of corroded building as $33 \%$. The failure mode of the first floor's columns turns to the mode of shear from flexure by corrosion, and the load carried by the columns on the first floor is redistributed to other columns.

In order to evaluate the effect of local corrosion on the structural system, one sensitivity analysis is carried out so that reinforcing bars of the columns of the first floor is corroded but the rest of columns are free from corrosion. The mass loss of the corroded reinforcing bars is tried to be $30 \%$ similar to the previous section.

The analytical result is shown in Fig. 17. When only columns on the first floor are corroded, the drift of the second floor becomes larger than the non-corroded case. The influence of the location of corrosion is summarized in Fig. 18. This graph shows the displacement of each floor in horizontal $\mathrm{Y}$ direction when the drift of the top floor reaches the maximum. As discussed previously, when the corrosion takes place on the whole columns, the load of the columns on the first floor is redistributed to the whole structural members. However, when the corrosion occurs only in the columns on the first floor, the drift of the second floor is $83 \%$, and it is much larger than the case where the whole columns are corroded.

From these analyses, the location of the corrosion has non-negligible influence on the macroscopic structural response. At the same time, local member capacity and ductility is damaged as well. As both micro and macro 


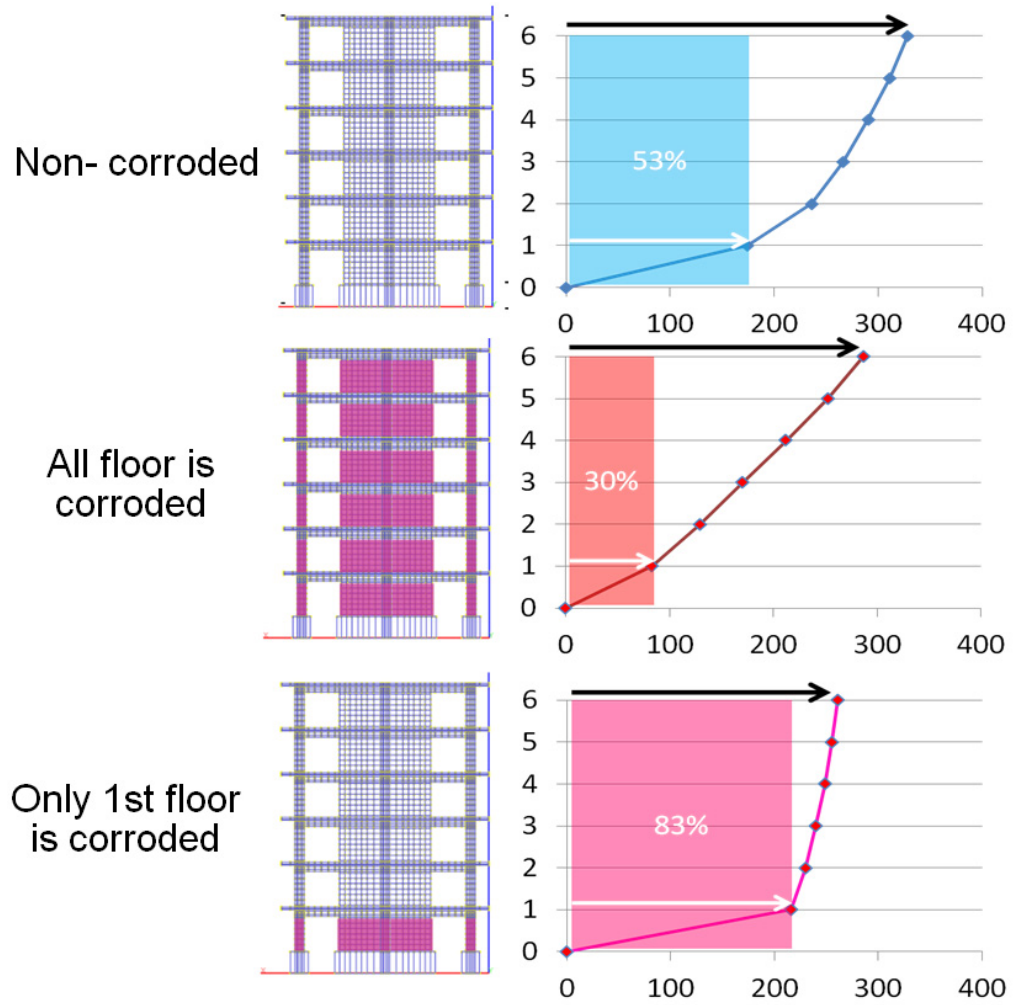

Fig. 18 Comparison of the effect of the location of the corrosion.

effects have a mutual interaction, it is impossible to categorically say some qualitative conclusion on corrosion impact to the structural systems. All factors from micro to macro scale events have to be consistently taken into account according to the structural detailing, input ground motions, used materials and the location and magnitude of corrosion.

\section{Concluding remarks}

The multi-scale thermo-hygro simulation is applied to both RC column members and a real-scale multi-story building. According to the authors' knowledge, this case study might be the first step to conduct the behavioral simulation of the full-scale building under the coupled long term ambient (over hundred days) and the short term seismic actions (about few seconds), although some detailed verification and validation must be needed in future. To realize the huge degree-of-freedom computations, multi-thread parallel computation scheme is developed with the sequential process of multi-chemomechanistic events, and the following conclusions are obtained

(1) Some columns are computationally cured under wet and drying conditions and exposed to severe corrosive environments. After the numerical corrosion was produced around reinforcing bars of the column mockup, the alternate forces are applied under high axial compression. The behavioral simulation results are compared with those of experiments. The fair function is examined for steering some trials and case studies.

(2) The corrosion of reinforcing bars computationally brings about damage around the cover concrete and the predicted shear capacity of members is deteriorated when the high flexural capacity is assured. It is confirmed that the effect of corrosion on the member capacity and ductility is much greater than the impact of reduced cross-sectional areas.

(3) So called life-span simulation are applied to the real scale multi-story RC building. In order to clarify the effect of corrosion, first, the non-corrosive environment under both sealed and drying states is discussed. It is confirmed that the drying shrinkage induced self-equilibrated stress and initial cracking greatly affect the nonlinear seismic responses, because the thickness of constituent structural members is rather thin compared to civil-infrastructures.

(4) Seismic responses of the multi-story building and mode of vibration can be affected by the corrosion of reinforcing bars. As the corrosion of steel may change the stiffness of members as well as ductility, it does not always increase in the seismic responses of the macroscopic structure. It is computationally proven that steel corrosion, which generally causes reduced seismic performances of members, may also reduce the seismic input to the structural members owing to the varying stiffness. Then, it is concluded that the corrosion and drying effects have to be heuristically evaluated with micro and macro serial linkage.

At this moment, the computed results are within the 
case study. It is thought that they do not encompass the general conclusions of structural concrete, but factors to be focused on are presented for future study of real scale structures in view of the coupling of mechanical and ambient actions.

\section{Ackowledgement}

The authors express their sincere gratitude to Prof. T. Shimozato of Ryuku University for his kind and valuable suggestions, and extend their appreciation to $\mathrm{Mr}$. $\mathrm{K}$. Shibata and S. Homma, former graduate students of The University of Tokyo, for their site investigation. The authors appreciate K-NET for the ground motion record (http://www.kyoshin.bosai.go.jp/kyoshin/). This research was financially supported by JSPS KAKENHI Grant No.23226011.

\section{References}

Abruzzo, J., Matta, A. and Panariello, G., (2006). "Study of mitigation strategies for progressive collapse of a reinforced concrete commercial building." Journal of Performance of Construction Facilities, 20, Special Issue: Mitigating the potential for progressive disproportionate structural collapse, 384-390.

Andrade, C. and Alonso, C., (1993). "Cover cracking as a function of bar corrosion: Part I-Experimental test." Materials and Structures, 26, 453-464.

Arasato, Y., Yamakawa, T., Morishita, Y. and Tamaki, Y., (2003). "Experimental study on the seismic performance of RC columns damaged under natural exposure." Proceedings of JCI, 25(2), 259-264. (in Japanese)

Asamoto, S., Ishida, T. and Maekawa, K., (2006). "Time-dependent constitutive model of solidifying concrete based on thermodynamic state of moisture in fine pores." Journal of Advanced Concrete Technology, 4(2), 301-323.

Cabrera, J. G., (1996). "Deterioration of concrete due to reinforcement steel corrosion." Cement and Concrete Composites, 18, 47-59.

Chijiwa, N., Kawanaka, I. and Makekawa, K., (2010). "The effect of strengthening the damage expected zone in a RC member with damaged anchorage." Journal of JSCE (E), 66(2), 179-192.

Chijiwa, N., Kawanaka, I. and Makekawa, K., (2011). "Effect of strengthening at expected damaging zone of an RC member with damaged anchorage." Journal of $J S C E$ (E2), 67(2), 160-165. (in Japanese)

Gebreyouhannes, E., Yoneda, T., Ishida, T. and Maekawa, K., (2014a). "Multi-scale based simulation of shear critical reinforced concrete beams subjected to drying." Journal of Advanced Concrete Technology, 12(10), 363-377.

Gebreyouhannes, E., Takahashi, Y., Maekawa, K., (2014b). "A poro-mechanical approach for assessing the structural impacts of corrosion in reinforced concrete members." Proc. of the 1st Ageing of Materials \& Structures, (Amsterdam), 354-362.
Gebreyouhannes, E. and Maekawa, K., (2011). "Numerical simulation on shear capacity and post-peak ductility of reinforced high-strength concrete coupled with autogenous shrinkage." Journal of Advanced Concrete Technology, 9(1), 73-88.

Izzuddin, B. A., Vlassis, A. G., Elghazouli, A. Y. and Nethercot, D. A., (2008). "Progressive collapse of multi-story buildings due to sudden column loss - Part I: Simplified assessment framework." Engineering Structures, 30(5), 1308-1318.

Japan Society of civil Engineers, (2012). "Standard Specification of Concrete Structures (design)." (in Japanese)

Lee, H. S., Noguchi, T. and Tomosawa, F., (1998). "Fundamental study on evaluation of structural performance of reinforced concrete beam damaged by corrosion of longitudinal tensile main rebar by finite element method." Transactions of AIJ, 506, 43-50. (in Japanese)

Matsumori, T., Kabeyazawa, T., Shirai, K. and Igarashi, K., (2008). "Shaking table test on a full-scale, six-story R/C building structure, Special project for earthquake disasters mitigation in urban areas in 2005, improvement of seismic performance of structures by E-Defense." Technical Note of the National Research Institute for Earth Science and Disaster Prevention, No.321.

Maekawa, K., Ishida, T. and Kishi, T., (2003). "Multi-scale modeling of concrete performance -Integrated material and structural mechanics-." Journal of Advanced Concrete Technology, 1(2), 91-126.

Maekawa, K., Ishida, T. and Kishi, T., (2008). "Multi-scale modeling of structural concrete." Taylor and Francis.

Maeshima, T., Koda, Y., Tsuchiya, S. and Iwaki, I., (2014). "Influence of corrosion of rebars caused by chloride induced determination on fatigue resistance in road bridge deck." Journal of Japan Society of Civil Engineers, Ser.E2, 70(4), 208-225. (in Japanese)

Michel, A., Pease, B. J., Peterová, A., Geiker, M. R., Stang, H. and Thybo, A. A. (2013). "Penetration of corrosion products and corrosion-induced cracking in reinforced cementitious materials: Experimental investigations and numerical simulations." Cement and Concrete Composites, 47, 75-86

Funaki, H., Yamakawa, T., Yamada, Y. and Nakata, K., (2008). "Horizontal cyclic loading test on the real-scale RC columns deteriorated under natural exposure in Okinawa." Proceedings of JCI, 30(3), 139-144. (in Japanese)

Sato, Y., Yamamoto, T., Hattori, A. and Miyagawa, T. (2003). "Shear behavior of RC member with corroded shear and longitudinal reinforcing steels." Proceedings of the JCI, 25(1), 821-826. (in Japanese)

Sawabe, S., Ueda, N., Nakamura, H. and Kunieda, M. (2006). "Shear failure behavior analysis of RC beam with unbonded region and decreased bond strength in 
stirrups." Journal of Materials, Concrete Structures and Pavements, JSCE, 62(2), 444-461. (in Japanese)

Okada, K., Kobayashi, K. and Miyagawa, T., (1988). "Influence of longitudinal cracking due to reinforcement corrosion on characteristics of reinforced concrete members." ACI Structural Journal, 85(2), 134-140.

Ouglova, A., Berthaud, Y., Francois, M. and Foct, F., (2006). "Mechanical properties of an iron oxide formed by corrosion in reinforced concrete structures." Corrosion Science, 48, 3988-4000.

Oh, B. H., Kim, K. H. and Jang, B. S., (2009). "Critical corrosion amount to cause cracking of reinforced concrete structures." ACI Material Journal, 106(4), 333-339.

Shimomura, T., Saito, S., Takahashi, R. and Shiba, A., (2011). "Modelling and nonlinear FE analysis of deteriorated existing concrete structures based on inspection." Modelling of Corroding Concrete Structures, RILEM Bookseries, 5, 259-272.

Takaya, S., Nakamura, S., Yamamoto, T. and Miyagawa, T., (2013). "Influence of steel corrosion products in concrete on crack opening weight loss of corrosion." Journal of JSCE, 69(2), 154-165. (in Japanese)
Toongoenthong, K. and Maekawa, K., (2005). "Multi-mechanical approach to structural performance assessment of corroded RC member in shear." Journal of Advanced Concrete Technology, 3(1), 107-122.

Val, D. V., Chernin, L. and Stewart, M. G., (2009). "Experimental and numerical investigation of corrosion-induced cover cracking in reinforced concrete structures." Journal of Structural Engineering, ASCE, 135, 376-385.

Wong, H. S., Zhao, Y. X., Karimi, A. R., Buenfeld, N. R. and Jin, W. L., (2010). "On the penetration of corrosion products from reinforcing steel into concrete due to chloride-induced corrosion." Corrosion Science, 52, 2469-2480.

Xue, X. and Seki, H., (2010). "Influence of longitudinal bar corrosion on shear behavior of RC beams." Journal of Advanced Concrete Technology, 8(2), 145-156.

Yamamoto, T. and Miyagawa, T., (2007). "Mechanical performance of RC structural material and member deteriorated by corrosion of reinforcing steel." Journal of the Society of Materials Science, 56(8), 684-693. (in Japanese) 